\title{
Postsurgical Analgesic Efficacy of Epidural Nalbuphine in Lower Abdominal Surgeries
}

\author{
Shivani Tejas Dalal ${ }^{1}$, Sanjot Ninave ${ }^{2}$ \\ ${ }^{1}$ Department of Anaesthesiology, Archarya Vinobha Bhave Rural Hospital, JNMC, DMIMS, Wardha, \\ Sawangi, Maharashtra, India. ${ }^{2}$ Department of Anaesthesiology, Archarya Vinobha Bhave Rural \\ Hospital, JNMC, DMIMS, Wardha, Sawangi, Maharashtra, India.
}

\section{ABSTRACT}

\section{BACKGROUND}

Epidural analgesia has been the gold standard, preferred technique for providing postoperative analgesia in lower abdominal, lower limb, pelvic and vascular surgeries. Combination of local anaesthetic agents when used along with opioids, as an adjuvant in epidural analgesia, was found to be effective and synergistic. Ropivacaine is associated with less central nervous system toxicity and cardiotoxicity, and produces less motor blockade. Nalbuphine is an opioid with mixed kappa $(\kappa)$ agonist and $\mathrm{mu}(\mu)$ antagonistic properties, when mixed with other opioids, attenuates the $\mu$ opioid effect and enhances the $\kappa$ opioid effect. We wanted to compare the post-surgical analgesic efficacy of epidural nalbuphine $(10 \mathrm{mg})$ when added as an adjuvant to epidural ropivacaine $(0.2 \%-9 \mathrm{ml})$ in patients undergoing lower abdominal surgeries. Primary objective was to compare the duration of postoperative analgesia and number of rescue analgesics required in 24 hours. Secondary objectives were to compare postoperative haemodynamic variation, quality of analgesia, Visual Analogue Score and side effects if any in both the groups.

\section{METHODS}

It was prospective observational study conducted after obtaining ethical committee clearance. Sixty patients of ASA class I \& II, fulfilling inclusion criteria posted for elective lower abdominal surgeries preferably abdominal hysterectomies divided into two groups, each comprising of 30 patients; group R- Ropivacaine- $0.2 \%-9 \mathrm{ml}$ with $1 \mathrm{ml}$ normal saline and group $\mathrm{R}+\mathrm{N}-0.2 \%$ - $9 \mathrm{ml}$ with nalbuphine $1 \mathrm{ml}-10 \mathrm{mg}$, under spinal anaesthesia with epidural catheter insertion. Parameters like duration of analgesia, number of rescue analgesia, quality of analgesia by patient rated quality of pain management, haemodynamic variation was assessed. Assessment of pain was done by VAS scale, side effects like sedation was assessed by modified Ramsay sedation scale.

\section{RESULTS}

No demographic variation was found in any group. Mean duration of analgesia was found more in group $\mathrm{R}+\mathrm{N}$. Number of rescue analgesia was reduced in group $\mathrm{R}+\mathrm{N}$ with improved quality of analgesia which was statistically significant. Mean HR was significant in group $\mathrm{R}+\mathrm{N}$. No change was noted in $\mathrm{SBP}, \mathrm{RR}, \mathrm{SpO}_{2}$ in either group. DBP and MAP showed statistically significant difference at 30, $60 \mathrm{~min}$ and 15, 30,60 min respectively. None of the patients in either group had sedation; one episode of vomiting was noted in group $\mathrm{R}+\mathrm{N}$ with statistically non-significant results.

\section{CONCLUSIONS}

Epidural Nalbuphine- $10 \mathrm{mg}$ when added as adjuvant with $0.2 \%$ Ropivacaine- $9 \mathrm{ml}$ improves duration and quality of analgesia with reduction in rescue analgesia and side effects with haemodynamic stability.

\section{KEY WORDS}

Postoperative Analgesia, Epidural Analgesia, Ropivacaine, Nalbuphine, Lower Abdominal Surgeries- Abdominal Hysterectomies

\begin{abstract}
Corresponding Author: Sanjot Ninave, JNMC Campus, DMIMS, Wardha, Sawangi (M), Maharashtra, India. E-mail: drsusann02@rediffmail.com

DOI: 10.14260/jemds/2020/50

Financial or Other Competing Interests: None.

How to Cite This Article:

Dalal ST, Ninave S. Postsurgical analgesic efficacy of epidural nalbuphine in lower abdominal surgeries. J. Evolution Med. Dent. Sci. 2020;9(04):216-222, DOI: $10.14260 / \mathrm{jemds} / 2020 / 50$
\end{abstract}

Submission 28-11-2019,

Peer Review 06-01-2020,

Acceptance 12-01-2020,

Published 27-01-2020. 


\section{BACKGROUND}

Pain is defined by International Association for the Study of Pain (IASP) as "an unpleasant sensory and emotional experience associated with actual or potential tissue damage or described in terms of such damage."(1) New revised definition of pain by Milton Cohen, John Quintner, and Simon van Rysewyk: "Pain is a mutually recognizable somatic experience that reflects a person's apprehension of threat to their bodily or existential integrity."(2),(3) Pain consist of four basic components, which defines its manifestation too: sensory- discriminative component - affective (emotional) component - vegetative (autonomic) component - motor component.(4) Relief from postoperative pain is a prerequisite for patient comfort, early mobilization, faster recovery which also helps to reduce incidences of cardiovascular and thrombo-embolic events.(5) Spinal anaesthesia provides an efficient block but has some disadvantages like height of block cannot be controlled, duration of block is constant and cannot be prolonged and is associated with complications such as post-dural puncture headache, neurological complications.

Epidural analgesia has been the gold standard and extensively preferred technique for providing postoperative analgesia in lower abdominal, lower limb, pelvic and vascular surgeries where complications are very less as compared to spinal anaesthesia. Also, there is no limitation for the duration of surgery if an epidural catheter is placed which further can be used for providing postoperative analgesia. The synergistic effect of local anaesthetics with opioid is because opioids decrease noxious stimuli arriving at the dorsal horn neuron and local anaesthetics reduce excitability of cell. Advantages of this combination includes effective pain relief, motor sparing.

Different adjuvants like opioids (morphine, buprenorphine, fentanyl, pethidine,(6) tramadol,(7) nalbuphine,(8)) ketamine,(9) midazolam,(10) alpha- 2 adrenergic agonist (clonidine,(11) dexmedetomidine ${ }^{(11)}$ ) have been used along with bupivacaine and ropivacaine with varied effects. Bupivacaine is a potent long acting amide, a local anaesthetic agent for epidural analgesia but has high chance of cardiac toxicity after accidental intravascular injection and cause motor blockade.(12),(13) Because of narrow cardiovascular collapse/central nervous system toxicity ratio(cc/cns) ${ }^{(14)}$ it has led to discovery of newer local anaesthetics with similar efficacy but less motor block and less cardiotoxicity, such as Ropivacaine. It is an long acting amino-amide local anaesthetic agent, chemically homologous to Bupivacaine,(15) and is increasingly replacing bupivacaine for postoperative analgesia(16). It is less lipophilic which is associated with less central nervous system toxicity and cardiotoxicity, produces less motor blockade, as it is more selective for sensory fibres and reduced penetration in large myelinated motor fibres.(17). The optimum dose of Ropivacaine for epidural analgesia is $2 \mathrm{mg} / \mathrm{ml}$.

Nalbuphine, a derivative of 14-hydroxy morphine is a opioid with mixed kappa $(\kappa)$ agonist and $m u(\mu)$ antagonistic properties. Action on kappa receptor assign a good sedative property, whereas partial agonism at the mu receptor induces a ceiling effect on respiratory depression, also has quality to potentiate action of local anaesthetic agents, Once given epidurally it exerts its action by interacting with its opioid receptor present on spinal cord. It is a strong analgesic with mixed $\kappa$ agonist and $\mu$ antagonist property, act principally on kappa receptor. It decreases the incidence of pruritis. It is effective for the prevention of epidural Morphine induced pruritis which occurs via agonism at the $\mu$ receptors Site of action in spinal cord is substantia gelatinosa.(18)

This study is undertaken to prove effectiveness of epidural nalbuphine $10 \mathrm{mg}$ as an adjuvant when added to local anaesthetic agent $0.2 \%$ ropivacaine $9 \mathrm{ml}$ to improve duration and quality of analgesia, reduce number of rescue analgesics in 24 hours and also any side effect like nausea, vomiting, pruritis, shivering, sedation associated with drug nalbuphine, as there are few study done with such combination.

\section{METHODS}

This prospective randomized study was conducted in the department of Anaesthesiology Acharya Vinobha Bhave Rural Hospital, Sawangi, Wardha attached to Jawaharlal Nehru Medical College over the period of two years from August 2017 to October 2019. After institutional and ethical committee clearance and written informed consent was obtained, 60 female patients divided into 2 groups of 30 each by computer generated random number table, willing to participate in elective lower abdominal surgery- abdominal hysterectomies within duration of 3 hours of age group - 3075 year, weight- $50-70 \mathrm{~kg}$, height- $148 \mathrm{~cm}-168 \mathrm{~cm}$, ASA class I-II, MPC grade I and II, normotensive with no other comorbidities were included in this prospective observational study, under spinal and epidural anaesthesia. Group Rpatient received- epidural $0.2 \%$ Ropivacaine $-9 \mathrm{ml}(18 \mathrm{mg})+$ $1 \mathrm{ml}$ normal saline and Group $\mathrm{R}+\mathrm{N}$ - patient receivedepidural $0.2 \%$ Ropivacaine $-9 \mathrm{ml}(18 \mathrm{mg})+$ Nalbuphine- $1 \mathrm{ml}$ (10 mg). Total volume in both the groups was- $10 \mathrm{ml}$. Preanaesthetic evaluation was done a day before surgery. On the arrival of the patient who fits the inclusion criteria for the study, in operating room, nil by mouth of 8 hours was confirmed. A $18 \mathrm{G}$ intravenous cannula was secured over forearm and infusion of ringer lactate/normal saline fluid was started at the rate of $15-20 \mathrm{ml} / \mathrm{kg}$. All the routine monitors were attached to the patient and baseline parameters were recorded like $\mathrm{HR}, \mathrm{SBP}, \mathrm{DBP}, \mathrm{MAP}, \mathrm{RR}, \mathrm{SPO}_{2}$, ECG.

Under aseptic precautions, Epidural insertion was started in sitting position using midline approach, at the level of L2 - L3, epidural space was localized and confirmed with loss of resistance technique (LOR) to air using $18 \mathrm{G}$ Touhy needle, hanging drop was also done to confirm catheter in epidural space. An epidural catheter was then inserted into epidural space in a cephalic direction, where the tip of the catheter was at level $\mathrm{T}_{8}$, then aspirated for detection of cerebrospinal fluid or blood, meniscus test was also performed. After the catheter was secured, a test dose of $3 \mathrm{ml}$ of $2 \%$ lignocaine with 1:2,00,000 adrenaline was injected after aspiration. After ruling out intrathecal and intravascular placement catheter was then fixed. Continuing in sitting position, under aseptic technique, Subarachnoid block was performed using 25G spinal Quincke's needle by midline approach, lumbar puncture was done at $\mathrm{L}_{3}-\mathrm{L}_{4}$ and 
inj. Bupivacaine $0.5 \%$ (Heavy)- $0.4 \mathrm{mg} / \mathrm{kg}$ was given without any adjuvant. Patients were then returned to supine position. Once the level of $\mathrm{T}_{6}$ was confirmed, surgery was allowed to start and was performed in any conventional manner. Intraoperatively monitoring of vitals was done, intraoperative fluid and blood loss was replaced using ringer lactate, packed red cells or whole blood. None of the patients were given intravenous analgesia throughout the surgery.

Once the surgery was over and patient shifted to postoperative room multipara monitors NIBP (SBP, DBP, $\mathrm{MAP}$ ), ECG, $\mathrm{SPO}_{2}$, $\mathrm{RR}$ was connected and monitored. The time when patient first complained of pain and found to be VAS score 4-5 the study was started and either of the drug was given with the spinal level sensory regression of $\mathrm{T}_{12}$ and vitals were recorded at 0 (baseline), 5, 10, 15, 30 and till 60 minutes in the postoperative room. Rescue analgesia/Supplementary analgesia was given by inj. Diclofenac $75 \mathrm{mg} \mathrm{IM}$, if patient not relieved of pain after first epidural analgesic dose.

Side effects like nausea, vomiting, pruritis, shivering, sedation, respiratory depression was observed. Duration of analgesia was measured from first epidural injection of either drug (VAS $\leq 4)$ until the subsequent complaint of pain (VAS $\geq 4$ ). The number of rescue analgesia given after the first epidural drug was noted. The total Rescue analgesic consumption in first 24 hours after first epidural analgesic drug was recorded in terms of number of doses and total dose in mg. Assessment of pain by visual analogue score (VAS) during first epidural injection of either drugs. Sedation was assessed by Modified Ramsay sedation scale: It was assessed from the study given at 0 (baseline), 5, 10, 15, 30, 60 minutes.

\begin{tabular}{|c|c|}
\hline \multicolumn{2}{|c|}{ Vas Score } \\
\hline \multicolumn{2}{|c|}{ Patient Rated Quality of Pain Management } \\
\hline 4. & Excellent \\
\hline 3. & Good \\
\hline 2. & Fair \\
\hline 1. & Poor \\
\hline \multicolumn{2}{|c|}{ Ability of the epidural drug to provide pain relief for long duration } \\
\hline \multicolumn{2}{|c|}{ Quality of Analgesia } \\
\hline
\end{tabular}

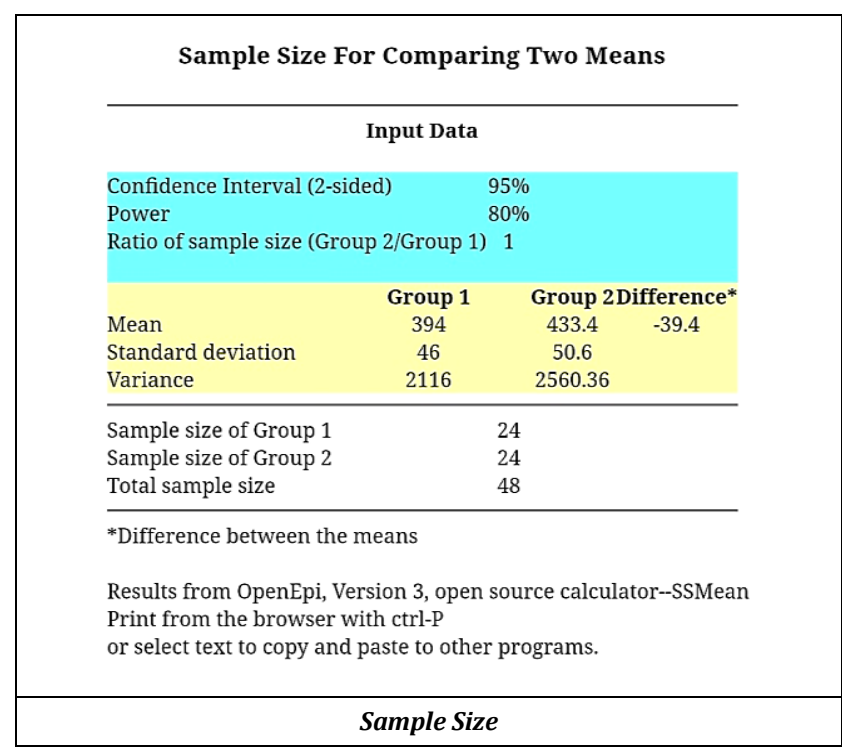

\section{Statistical Analysis}

Statistical analysis was done using descriptive and analytical statistics. The chi square test was used to check differences in proportions. Continuous variables are expressed as mean and standard deviation. The normality of continuous data was analysed by the Shapiro- Wilk test. As the data followed normal distribution, parametric test (t-test) was used to analyse the data. The independent sample t- test was used to check mean difference. The level of significance was kept at $p<0.05$. Assuming the average duration of analgesia of 394 min and standard deviation of $46 \mathrm{~min}$ (with reference to study done by Anil P Singh(7) et al), keeping power at $80 \%$ and confidence interval at 95\% (alpha error at 0.05), a sample size of 24 patients would be required to detect a minimum of $10 \%$ difference in duration of analgesia between 2 groups. We included 30 patients in each group to compensate for possible drop out.

\section{RESULTS}

\begin{tabular}{|c|c|c|c|c|c|c|c|c|}
\hline Variable & \multicolumn{3}{|c|}{ Group R (n=30) } & \multicolumn{4}{|c|}{ Group $R+N(n=30)$} & \multirow[t]{2}{*}{ p } \\
\hline & \begin{tabular}{l|l} 
Mean & \\
\end{tabular} & \multicolumn{2}{|c|}{ S.D. } & \multicolumn{2}{|c|}{ Mean } & \multicolumn{2}{|c|}{ S.D. } & \\
\hline Age (Years) & 45.20 & \multicolumn{2}{|c|}{9.48} & \multicolumn{2}{|c|}{45.76} & \multicolumn{2}{|c|}{6.89} & $0.792, \mathrm{NS}$ \\
\hline Weight (Kgs.) & 57.70 & \multicolumn{2}{|c|}{4.12} & \multicolumn{2}{|c|}{58.13} & \multicolumn{2}{|c|}{4.56} & $0.701, \mathrm{NS}$ \\
\hline Height (cms.) & 153.06 & \multicolumn{2}{|c|}{4.91} & \multicolumn{2}{|c|}{154.80} & \multicolumn{2}{|c|}{3.79} & $0.132, \mathrm{NS}$ \\
\hline \multicolumn{9}{|c|}{ Table 1. Demographic Data of the Study Population } \\
\hline \multicolumn{9}{|c|}{$\begin{array}{l}\mathrm{N}=\text { number; all values are expressed as mean and standard deviation, } \mathrm{p}<0.05 \text { is } \\
\text { significant, } \mathrm{S}=\text { significant; NS=non-significant. }\end{array}$} \\
\hline \multirow{2}{*}{\multicolumn{2}{|c|}{ Variable }} & \multicolumn{2}{|c|}{ Group R } & \multicolumn{3}{|c|}{ Group R+N } & & \multirow{2}{*}{$\mathbf{p}$} \\
\hline & & $\mathbf{N}$ & Mean & S.D. & $\mathbf{N}$ & Mean & S.D. & \\
\hline Duration & f Analgesia & 30 & 4.68 & 0.62 & 30 & 11.56 & 1.25 & $<0.001, \mathrm{~S}$ \\
\hline \begin{tabular}{l|l}
$2 \mathrm{~B}$ & No. of Res \\
\end{tabular} & ue Analgesia & 30 & 2.86 & 0.50 & 30 & 1.40 & 0.62 & $<0.001, \mathrm{~S}$ \\
\hline \begin{tabular}{l|l}
$2 \mathrm{C}$ & Quality \\
\end{tabular} & f Analgesia & 30 & 2.06 & 0.63 & 30 & 3.53 & 0.50 & $<0.001$, S \\
\hline \multicolumn{9}{|c|}{$\begin{array}{c}\text { Table 2. Comparison of Mean Duration of Analgesia, Number of Rescue } \\
\text { Analgesia and Quality of Analgesia between the Two Groups }\end{array}$} \\
\hline \multirow{2}{*}{\multicolumn{2}{|c|}{ Quality of Analgesia }} & \multicolumn{2}{|c|}{ Group R } & \multicolumn{3}{|c|}{ Group R+N } & \multicolumn{2}{|r|}{ p } \\
\hline & & \multicolumn{2}{|c|}{ N (\%) } & & $\mathbf{N}(\%$ & & & \\
\hline \multicolumn{2}{|c|}{ Excellent } & & $0.0)$ & & $16(5)$ & & & $0.001, \mathrm{~S}$ \\
\hline & & & $23.3)$ & & $14(4$ & & & \\
\hline & & & $60.0)$ & & $0(0$. & & & \\
\hline & & & 16.7) & & $0(0$. & & & \\
\hline Table & Comparis & & $\begin{array}{l}\text { atient } 1 \\
\text { the } T \text { t }\end{array}$ & Dated & $Q-Q u$ & ality of & nala & esia \\
\hline
\end{tabular}

\begin{tabular}{|c|c|c|c|c|c|c|c|c|c|c|c|c|c|c|c|}
\hline & \multicolumn{5}{|c|}{ HR } & \multicolumn{5}{|c|}{ DBP } & \multicolumn{5}{|c|}{ MAP } \\
\hline & \multicolumn{2}{|c|}{ Group R } & \multicolumn{2}{|c|}{ Group $\mathrm{R}+\mathrm{N}$} & \multirow[b]{2}{*}{$=$} & \multicolumn{4}{|c|}{\begin{tabular}{|l|l|} 
Group R & Group $\mathrm{R}+\mathrm{N}$ \\
\end{tabular}} & \multirow{2}{*}{ ב气 } & \multicolumn{4}{|c|}{ Group Riroup $\mathrm{R}+\mathbf{N}$} & \\
\hline & $\begin{array}{l}\text { ॠ } \\
\frac{0}{\Sigma}\end{array}$ & के & 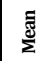 & जे & & 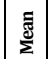 & ติ & 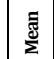 & के & & $\frac{\mathbb{d}}{\Sigma}$ & ผें & 丞 & के & \\
\hline Pre-op & 80.73 & 6.72 & 78.46 & 5.08 & $0.146, \mathrm{NS}$ & 81.13 & 5.98 & 79.33 & 5.10 & $0.215, \mathrm{NS}$ & 94.93 & 5.18 & 93.26 & 3.71 & $0.158, \mathrm{~N}$ \\
\hline Baseline & 82.40 & 5.81 & 81.80 & 5.28 & $0.677, \mathrm{NS}$ & 84.33 & 5.30 & 82.40 & 4.93 & $0.149, \mathrm{NS}$ & 98.51 & 4.66 & 96.73 & 3.60 & $0.104, \mathrm{NS}$ \\
\hline $5 \mathrm{~min}$ & 85.46 & 5.98 & 81.80 & 5.28 & $0.015, \mathrm{~S}$ & 84.53 & 5.60 & 82.40 & 4.93 & $0.123, \mathrm{NS}$ & S98.64 & 4.87 & 96.84 & 3.52 & $0.107, \mathrm{NS}$ \\
\hline $10 \mathrm{~min}$ & 85.20 & 5.88 & 81.13 & 5.05 & $0.006, \mathrm{~S}$ & 84.13 & 5.50 & 82.06 & 4.79 & $0.127, \mathrm{NS}$ & 998.24 & 4.72 & 96.44 & 3.40 & $0.096, \mathrm{NS}$ \\
\hline $15 \mathrm{~min}$ & 84.53 & 5.94 & \begin{tabular}{|l|l|}
80.33 \\
\end{tabular} & 4.84 & \begin{tabular}{|l|}
$0.004, \mathrm{~S}$ \\
\end{tabular} & 83.53 & \begin{tabular}{|l|}
5.11 \\
\end{tabular} & 81.13 & 4.89 & $0.068, \mathrm{NS}$ & 997.62 & 4.52 & 95.48 & 3.48 & $0.045, \mathrm{~S}$ \\
\hline $30 \mathrm{~min}$ & 83.60 & 6.28 & 79.40 & 5.04 & $0.006, \mathrm{~S}$ & 83.13 & \begin{tabular}{|l|}
4.89 \\
\end{tabular} & 80.20 & 4.76 & $0.022, \mathrm{~S}$ & 97.11 & 4.26 & 94.51 & 3.36 & $0.011, \mathrm{~S}$ \\
\hline $60 \mathrm{~min}$ & 83.40 & 6.26 & 78.86 & 5.05 & $0.003, \mathrm{~S}$ & 82.66 & 4.82 & 79.80 & 4.93 & $0.027, \mathrm{~S}$ & 96.66 & 4.23 & 94.11 & 13.63 & $0.015, \mathrm{~S}$ \\
\hline & & & & & 140 & & e Int & & & & & & & & \\
\hline
\end{tabular}

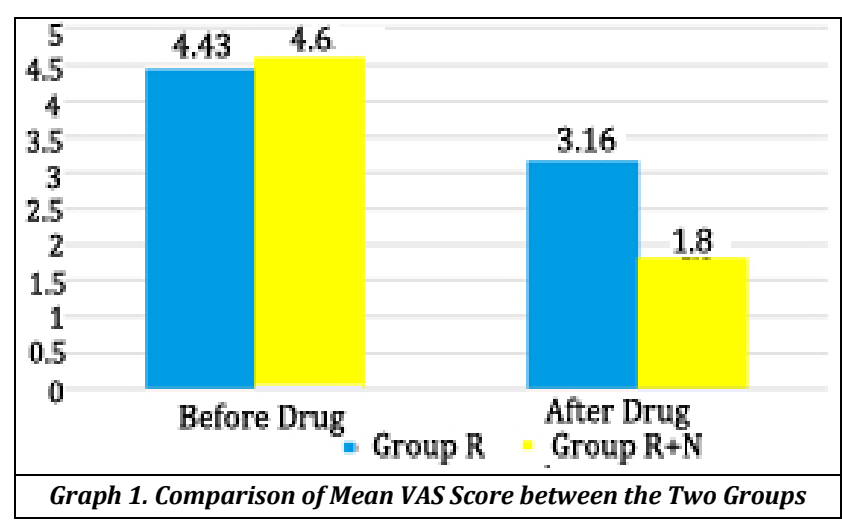


Comparison of Mean Systolic Blood pressure between the two groups at various time intervals did not show any significant difference and results were statistically nonsignificant. Comparison of Mean Respiratory Rate and $\mathrm{SPO}_{2}$ between the two groups at various time intervals did not show any significant difference and results were statistically non-significant.

\section{DISCUSSION}

Local anaesthetic act by blocking voltage gated sodium channels which prevents initiation and propagation of nerve impulse. Dorsal horn nociceptive neurons exhibit wind up a frequency dependent potentiation of their responses to repeated " $\mathrm{C}$ " fibre stimulation. Opioids reduce the release of primary afferent transmitters via inhibitory presynaptic opioid receptors on "C" fibre terminals. Thus blocking " $\mathrm{C}$ " fibre stimulation of the dorsal horn nociceptive neurons and delaying the onset of wind up. In combination with a small dose of opioids, threshold doses of local anaesthetics markedly reduce the " $\mathrm{C}$ " fibres evoked response compared with either drug alone. The synergistic effect leads to reduced noxious stimuli arriving at the dorsal horn neuron by opioids and the local anaesthetic to reduce the excitability of these cells.(19)

\section{Demographic Data}

Table 1 shows the demographic distribution mean age, mean weight, mean height and was found that there was no statistically significant difference.

\section{Duration of Analgesia, Rescue Analgesia, and Quality of Analgesia}

In table $2(2 \mathrm{~A})$ the duration of analgesia in group $\mathrm{R}$ was 4.68 $\pm 0.62 \mathrm{hr}(280.8 \mathrm{~min})$ and in group $\mathrm{R}+\mathrm{N}$ was $11.56 \pm 1.25 \mathrm{hr}$ (693.6 min) which is statistically significant $(\mathrm{p}<0.001)$ and is similar to an observation by P. Sateesh(19) in 2015 where epidural Nalbuphine $-0.2 \mathrm{mg} / \mathrm{kg}$ added as adjuvant to epidural $0.5 \%$ bupivacaine showed early onset of analgesia(3.23 \pm 0.97 mins) and prolong duration of action (449.67 \pm 39.43 mins) and result was statistically significant. In similar study by Biswajit Sutradhar(20) et al in 2017 used Ropivacaine $0.75 \% 9 \mathrm{ml}+$ Lignocaine $0.2 \% 3 \mathrm{ml}$. Ropivacaine $0.2 \% 8 \mathrm{ml}$ and Nalbuphine $10 \mathrm{mg}(1 \mathrm{ml})$ or Tramadol $50 \mathrm{mg}$ (1 ml), mean duration of analgesia with Nalbuphine was $416 \pm 38$ min and with Tramadol was $211 \pm 29$ min with $P$ value of 0.001 which was highly significant and similar to our result where for nalbuphine group duration was $11.56 \pm 1.25$ $\mathrm{hr}$ (693.6 $\mathrm{min}$ ) as compared to plane ropivacaine group was $4.68 \pm 0.62 \mathrm{hr}(280.8 \mathrm{~min})$. Thus, nalbuphine added to ropivacaine prolongs duration of analgesia as compared to ropivacaine alone. In a study by Kataria $\mathrm{AP}(21)$ in 2018 observed nalbuphine $0.8 \mathrm{mg}$ when added to bupivacaine intrathecally prolongs the duration of analgesia by $290 \pm 6.09$ minutes as compared to ketamine $25 \mathrm{mg}$ added to bupivacaine showed $220 \pm 5.03$ minutes which is consistent with our study results that epidural nalbuphine added to ropivacaine prolongs the duration of analgesia by $11.56 \pm 1.25$ hour (693.6 minutes).

\section{Number of Rescue/Top Ups}

In table $2(2 \mathrm{~B})$ the number of rescue analgesia was 2.86 in group $\mathrm{R}$ and in group $\mathrm{R}+\mathrm{N}$ was 1.40 which showed statistically significant result $(\mathrm{p}<0.001)$ which was similar to study by Saravana Babu(22) in 2017 where they used $0.2 \%$ ropivacaine $+2 \mathrm{mg}$ butorphanol to compare with $0.2 \%$ ropivacaine $+10 \mathrm{mg}$ nalbuphine through thoracic epidural catheter. Nalbuphine group showed good quality of analgesia and stable cardiorespiratory parameters for the initial 6 hours of postoperative period, after which they were comparable in both groups. Also, the requirement of rescue analgesia was higher (20\%) in the butorphanol group during the first 6 hour, which was similar to our study showed reduced requirement of rescue analgesia in nalbuphine group. Similar study by Nama Nagarjuna Chakravarthy(23) et al in 2018 used epidural Nalbuphine $(10 \mathrm{mg}$ ) with $0.5 \%$ bupivacaine and epidural fentanyl $(50 \mu \mathrm{g})$ with $0.5 \%$ bupivacaine in lower abdominal and lower limb surgeries, the number of rescue analgesics required in the first 24 hours of post-operative period was more with fentanyl group as compared to nalbuphine group. Results were statistically significant $(p<0.01)$ which is similar to our study. In nalbuphine group requirement of number of rescue analgesia top up was less $(1.40 \pm 0.62)$ when compared to plane ropivacaine group $(2.86 \pm 0.50)$ which was statistically significant. Similar results were found in Saravana Babu(22) in 2017 showed reduction in rescue analgesia with nalbuphine when added to ropivacaine. So nalbuphine added to ropivacaine as adjuvant reduces the number of rescue analgesia as compared to ropivacaine alone. In study by Veena Chatrath(8) in 2015 showed the overall duration of postoperative analgesia was more in tramadol than in nalbuphine group, total number of top-up given in nalbuphine was $5.08 \pm 0.694$, as compared to $4.90 \pm 0.900$ in tramadol and the difference between the two groups was found to be statistically non-significant which is inconsistent with our result that number of rescue analgesia in nalbuphine group was $1.40 \pm 0.62$ and the results were statistically significant.

\section{Quality of Analgesia}

In table $2(2 \mathrm{C})$ the mean quality of analgesia score was significantly higher $(\mathrm{p}<0.001)$ in group $\mathrm{R}+\mathrm{N}(3.53 \pm 0.50)$ than the group $R(2.06 \pm 0.63)$ which is statistically significant. In table 3 the Patient rated - quality of analgesia between the two groups was compared. The chi-square test showed statistically significant differences $(\mathrm{p}<0.001)$ in quality of analgesia scores between the two groups. In group $\mathrm{R}+\mathrm{N}$, $53.3 \%$ subjects had excellent quality of analgesia and $46.7 \%$ had good quality of analgesia. In contrary, in group R, none of the subjects had excellent analgesia, $23.3 \%$ had good analgesia, $60 \%$ of them had fair and $16.7 \%$ had poor analgesia. Scott, David $\mathrm{A}^{(24)}$ used epidural Ropivacaine 2 $\mathrm{mg} / \mathrm{mL}$ alone and Ropivacaine $2 \mathrm{mg} / \mathrm{ml}$ with fentanyl $(1,2,4$ $\mu \mathrm{gs} / \mathrm{ml}$ ) for postoperative analgesia- quality of pain relief was measured in three ways- vas score, Pain relief $=$ patientrated quality of pain management (1=poor, 2=fair, 3=good, $4=$ excellent), Ability of the epidural infusion to provide pain relief for long duration as opioids provide analgesia to areas which are not covered by the spread in the epidural space and also epidural opioid has synergistic action with the local anaesthetic agents which will compensate for unilateral or 
patchy effect. In our study quality of analgesia which is one of the predictors for patient satisfaction was used same as above mentioned except for the epidural infusions and fentanyl, nalbuphine is used in our study along with ropivacaine which potentiates its analgesic action and showed superior results in nalbuphine group. In a similar study by Veena Chatrath(8) in 2015, though the mean duration of analgesia was similar in both nalbuphine and tramadol group but, nalbuphine group $(4.40 \pm 0.871)$ had patient satisfaction score higher as compared to tramadol group (3.90 1.150$)$. These findings are consistent with our results that overall patient satisfaction is better, that is better quality of analgesia with nalbuphine when given epidurally as adjuvant to local anaesthetic ropivacaine as compared to ropivacaine alone. Hence quality of postoperative analgesia was better with nalbuphine and results were consistent with the study by Saravana Babu(22) in 2017, showed earlier onset of action when nalbuphine added to ropivacaine as compared to butorphanol added to ropivacaine.

\section{Equipotency of Dose of Epidural Ropivacaine}

For postoperative analgesia, by Sara Korula(12) in 2011 used $0.2 \%$ ropivacaine and $0.125 \%$ bupivacaine as continuous epidural infusion showed no difference in the sensory block. Duration of motor block and VAS scores were similar in both groups during the post-operative period, with a similar motor block profile. So, the equipotent dose of ropivacaine and bupivacaine provides similar quality of analgesia, but degree of motor block is higher with bupivacaine. So, for our study ropivacaine $0.2 \% 10 \mathrm{ml}$ was used providing good analgesia without motor blockade. Nalbuphine is an opioid with agonistic kappa action and antagonistic action at $\mu$ receptors which helps in providing potent visceral analgesia.(8) In our study nalbuphine added as adjuvant to ropivacaine is found to be more potent and efficacious. In a similar study by Verma(25) in 2013 proved that nalbuphine when added to bupivacaine intrathecally improves postoperative analgesia, which is consistent with our result.

\section{Haemodynamic Parameters}

In table 4, results did not show any statistically significant difference for mean heart rate at pre-operatively $(p=0.146)$ and at baseline $(p=0.677)$. The mean heart rate of group $R$ was significantly more than the $\mathrm{R}+\mathrm{N}$ group at $5 \mathrm{~min}$ $(p=0.015), 10 \min (p=0.006), 15 \min (p=0.004), 30 \mathrm{~min}$ $(p=0.006)$ and 60 min $(p=0.003)$, but overall difference was minor. Haemodynamic stability with local anaesthetic especially with ropivacaine was maintained due to lower concentration of $0.2 \%$ ropivacaine effectively blocking pain impulses and autonomic and motor action was spared in our study. In a study by Bhavana $\mathrm{B}(26)$ in 2018 showed a significant difference in HR in intrathecal nalbuphine group as compared to intrathecal fentanyl group, also bradycardia (12.9\%) was also noted without hypotension but our study had no incidence of hypotension or bradycardia, in both the groups heart rate was maintained but statistically significant in group $\mathrm{R}+\mathrm{N}$ from $5 \mathrm{~min}(\mathrm{p}=0.015)$ to $60 \mathrm{~min}(\mathrm{p}=0.003)$. In a similar study by Saravana Babu(22) in 2017, showed that heart rate was significantly lower in nalbuphine group as compared to butorphanol group, which states that nalbuphine is better than butorphanol. The mean systolic blood pressure between the two groups at various time intervals was compared and the results did not show any statistically significant difference at $0 \mathrm{~min}, 5 \mathrm{~min}, 10 \mathrm{~min}, 15$ min, $30 \mathrm{~min}, 60 \mathrm{~min}$ intervals between the two groups $(p>0.05)$. Similar studies by Nama Nagarjuna Chakravarthy(23) in 2018, showed non-significant results in systolic $(p=0.36)$ and the results are consistent with our study at $5 \mathrm{~min}(\mathrm{p}=0.015), 10 \mathrm{~min}(\mathrm{p}=0.006), 15 \mathrm{~min}$ $(p=0.004), 30 \min (p=0.006), 60 \min (p=0.003)$ statistically significant. So Nalbuphine does not have any effect on SBP. In table 4 , The independent sample t-test did not show any statistically significant difference for mean diastolic blood pressure pre-operatively, baseline, at $5 \mathrm{~min}, 10 \mathrm{~min}$ and 15 min. The mean diastolic blood pressure was statistically significant in group $\mathrm{R}+\mathrm{N}$ than the group $\mathrm{R}$ at $30 \mathrm{~min}$ $(p=0.022)$ and at $60 \mathrm{~min}(\mathrm{p}=0.02)$. Similar studies by Nama Nagarjuna Chakravarthy(23) in 2018, showed non-significant results in diastolic blood pressures $(p=0.074)$ and the results are consistent with our study till 15 minutes $(p=0.068)$, then at 30 minute $(p=0.022)$ and at 60 minute $(p=0.027)$ which was statistically significant and returned to its preoperative values in group $\mathrm{R}+\mathrm{N}$. So nalbuphine does not have any hypotensive effect and maintains DBP in normal range.

In table 4, results did not show any statistically significant difference for mean arterial pressure at preoperatively $(\mathrm{p}=0.158)$ at baseline, 5 and 10 minutes. The mean arterial pressure of group $\mathrm{R}$ was significantly more than the $\mathrm{R}+\mathrm{N}$ group at $15 \min (\mathrm{p}=0.045), 30 \mathrm{~min}(\mathrm{p}=0.011)$ and $60 \mathrm{~min}(\mathrm{p}=0.015)$. In a similar study by Nama Nagarjuna Chakravarthy(23) in 2018 showed significant results at $3^{\text {rd, }}$ $6^{\text {th }}, 7^{\text {th }}, 8^{\text {th }}, 9^{\text {th }}$ and $10^{\text {th }}$ hour and at rest were non-significant which is inconsistent to our results that it showed statistically significant difference at $15 \mathrm{~min}(\mathrm{p}=0.045), 30$ $\min (\mathrm{p}=0.011)$ and $60 \mathrm{~min}(\mathrm{p}=0.015)$ after the study drug given. In a similar study by Saravana Babu(22) in 2017, showed that MAP was statistically significant in nalbuphine group which is consistent to our study at 15 $\min (95.48 \pm 3.48), \quad 30 \mathrm{~min}(94.51 \pm 3.36)$ and at 60 $\min (94.11 \pm 3.63)$. The mean respiratory rate between the two groups did not show any statistically significant difference between the two groups ( $p>0.05)$. Similar studies by Nama Nagarjuna Chakravarthy(23) in 2018, showed nonsignificant results in respiratory rate $(p=0.74)$ and the results are consistent with our study- from baseline $(\mathrm{p}=0.356)$ to $60 \mathrm{~min}(\mathrm{p}=0.112)$. The mean $\mathrm{SpO}_{2}$ between the two groups did not show any statistically significant difference $(p>0.05)$ and was similar to studies by Saravana

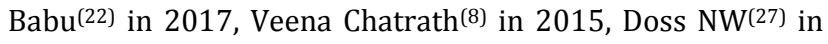
2001, Bhattacharyya R(28) in 2007.

\section{VAS}

In graph 1, the mean VAS score between the two groups was compared. Before administration of drug the mean VAS score was not statistically significant $(p=0.203)$. After administration of epidural analgesic drug the VAS score of group $\mathrm{R}+\mathrm{N}$ was significantly $(\mathrm{p}<0.001)$ lower than the group R. VAS score was significantly reduced in $\mathrm{R}+\mathrm{N} \quad 1.80 \pm 0.40$ which was statistically significant after the drug was injected and the VAS score reduced from 4 to VAS $=1-2$, our findings are consistent with study by Nama Nagarjuna Chakravarthy ${ }^{(23)}$ in 2018 showed VAS between 0-4 was more in nalbuphine + bupivacaine group as compared to fentanyl + bupivacaine. Study by Biswajit Sutradhar(20) in 2017, showed 
mean VAS score in nalbuphine group $(4.35 \pm 1.2)$ which is less and in tramadol group $(6.23 \pm 2.5)$ which was similar to our study results group $\mathrm{R}+\mathrm{N}(1.80 \pm 0.40)$. In a study by Saravana Babu(22) in 2017 showed similar results with our study, VAS score started decreasing after 15 min of drug administration and was lower in nalbuphine group as compared to butorphanol group.

\section{Side Effects/Sedation}

In our study none of the patients in either groups had sedation. In group $\mathrm{R}+\mathrm{N}$ only one patient (3.3\%) had vomiting. There was no statistically significant difference in any adverse effects between the two groups. In a similar study by Veena Chatrath( $\left.{ }^{8}\right)$ in 2015 , after injection of study drug sedation was observed more in tramadol group than in nalbuphine group. In study by P. Sateesh(19) in 2015 observed no sedation in either group of bupivacaine or bupivacaine with nalbuphine but other side effects like nausea/vomiting, pruritis, urinary retention in nalbuphine group and hypotension in both groups was present which was inconsistent with our study results. In a study by Nama Nagarjuna Chakravarthy(23) in 2018 side effects were more pronounced with bupivacaine + fentanyl group (nausea/vomiting-10\%, respiratory depression-13.3\%, hypotension-10\%, bradycardia- $6.6 \%$, shivering-6.6\%) as compared to bupivacaine + nalbuphine -nausea/vomiting$3.3 \%$ similar to our study result, hypotension-6.6\%, bradycardia-3.3\%, shivering-3.3\% none of these were noted in our study. In a similar study by Biswajit Sutradhar(20) in 2017 nausea and vomiting was observed more with ropivacaine + tramadol group $(57.78 \%)$ as compared to in ropivacaine + nalbuphine group $(0 \%)$ which was similar to our study. Sedation score was more in nalbuphine group $(1.37 \pm 0.02)$ as compared to tramadol group $(1.35 \pm 0.03)$ and the results were inconsistent with our study. Nalbuphine has partial agonistic action on $\mu$ subtype receptor responsible sedation which in this study was found to be advantageous as it produced arousable sedation. In a study by Sonali M Khobragade(18) in 2017 compared nalbuphine and dexmedetomidine as adjuvants added to bupivacaine$0.5 \% 15 \mathrm{ml}$ epidurally for lower limb surgeries found pain scores VAS was comparable in both groups, also no sedation was observed in any of the groups which is consistent with our study results.

\section{CONCLUSIONS}

Epidural nalbuphine $10 \mathrm{mg}$ when added as an adjuvant to $0.2 \%$ ropivacaine $9 \mathrm{ml}$ for postoperative analgesia in patients undergoing lower abdominal surgery mainly abdominal hysterectomies, increases the duration of postoperative analgesia, reduces the number of rescue analgesics, maintains haemodynamic stability, improves VAS score, has minimal side effects and gives overall patient satisfaction.

\section{REFERENCES}

[1] Rajagopal MR. Pain - basic considerations. Indian J Anaesth 2006;50(5):331-4.
[2] Cohen M, Quintner J, Van Rysewyk S. Reconsidering the international association for the study of pain definition of pain. Pain Reports 2018;3(2):e634.

[3] Treede RD. The International Association for the Study of Pain definition of pain: as valid in 2018 as in 1979, but in need of regularly updated footnotes. Pain Reports 2018;3(2):e643.

[4] Malek J, Sevcik P. Post-operative pain management book. Chap - 2. Pathophysiology of postoperative pain and postoperative analgesia. $3^{\text {rd }}$ edn. Prague: Mlada Fronta 2017;22:9,10-22.

[5] Iyer SS, Bavishi $\mathrm{H}$, Mohan CV, et al. Comparison of epidural analgesia with transversus abdominis plane analgesia for postoperative pain relief in patients undergoing lower abdominal surgery: a prospective randomized study. Anesth Essays Res 2017;11(3):6705.

[6] Golam KK, Pantvaidya SN, Jagtap SR. Epidural pethidine for post-operative pain relief after upper abdominal surgery. J Postgrad Med 1986;32(3):122-6.

[7] Singh AP, Singh D, Singh Y, et al. Postoperative analgesic efficacy of epidural tramadol as adjutant to ropivacaine in adult upper abdominal surgeries. Anesth Essays Res 2015;9(3):369-73.

[8] Chatrath V, Attri JP, Bala A, et al. Epidural nalbuphine for postoperative analgesia in orthopedic surgery. Anesth Essays Res 2015;9(3):326-30.

[9] Sethi M, Sethi N, Jain P, et al. Role of epidural ketamine for postoperative analgesia after upper abdominal surgery. Indian J Anaesth 2011;55(2):141-5.

[10] Nishiyama T, Matsukawa T, Hanaoka K. Effects of adding midazolam on the postoperative epidural analgesia with two different doses of bupivacaine. J Clin Anesth 2002;14(2):92-7.

[11] Bajwa SJS, Bajwa SK, Kaur J, et al. Dexmedetomidine and clonidine in epidural anaesthesia: a comparative evaluation. Indian J Anaesth 2011;55(2):116-21.

[12] Korula S, George GM, Ipe S, et al. Epidural anesthesia and post-operative analgesia for bilateral inguinal mesh hernioplasty: comparison of equipotent doses of ropivacaine and bupivacaine. Saudi J Anaesth 2011;5(3):277-81.

[13] Valecha D, Acharya G, Arora KK. 0.125\% Bupivacaine versus $0.2 \%$ ropivacaine for labour epidural analgesia: a comparative study. Int Journal Sci Res 2016;5(3):11503.

[14] Hansen TG. Ropivacaine: a pharmacological review. Expert Rev Neurother 2004;4(5):781-91.

[15] Whitehead E, Arrigoni B, Bannister J. An open study of ropivacaine in extradural anaesthesia. $\mathrm{Br} \mathrm{J}$ Anaesth 1990;64(1):67-71.

[16] Brockway MS, Bannister J, McClure JH, et al. Comparison of extradural ropivacaine and bupivacaine. $\mathrm{Br} \mathrm{J}$ Anaesth 1991;66(1):31-7.

[17] Kuthiala G, Chaudhary G. Ropivacaine: a review of its pharmacology and clinical use. Indian $J$ Anaesth 2011;55(2):104-10.

[18] Khobragade SM, Kalbhor J, Saran R, et al. A comparative study of dexmedetomidine and nalbuphine as an adjuvant to bupivacaine in lower limb surgeries doneunder epidural anaesthesia. MedPulse 
International Journal of Anesthesiology 2017;3(1):3442.

[19] Kumar PS, Sarma BA, Rao DBVM, et al. Comparison of nalbuphine with $0.5 \%$ bupivacaine and normal saline with $0.5 \%$ bupivacaine for post-operative epidural analgesia. J Evol Med Dent Sci 2015;4(48):8382-9.

[20] Sutradhar B, Majumder TH, Bhattacharjee H, et al. A comparative evaluation of ropivacaine with nalbuphine versus ropivacaine with tramadol for postoperative epidural analgesia in elective abdominal hysterectomy. Int Journal Curr Med Appl Sci 2017;13(2):107-11.

[21] Kataria AP, Singh H, Mohan B, et al. Intrathecal nalbuphine versus ketamine with hyperbaric bupivacaine in lower abdominal surgeries. Anesthesia Essays Researches 2018;12(2):366-70.

[22] Babu S, Gupta BK, Gautam GK. A comparative study for post-operative analgesia in the emergency laparotomies: thoracic epidural ropivacaine with nalbuphine and ropivacaine with butorphanol. Anesth Essays Res 2017;11(1):155-9.

[23] Chakravarthy NN, Sagar A, Venkateshwarlu G, et al. A comparative study of epidural $0.5 \%$ bupivacaine with nalbuphine and $0.5 \%$ bupivacaine with fentanyl in lower abdominal and lower limb surgeries. Int Arch Integr Med 2018;5(2):124-34.
[24] Scott DA, Blake D, Buckland M, et al. A comparison of epidural ropivacaine infusion alone and in combination with 1,2 , and $4 \mathrm{microg} / \mathrm{ml}$ fentanyl for seventy-two hours of postoperative analgesia after major abdominal surgery. Anesth Analg 1999;88(4):857-64.

[25] Verma D, Naithani U, Jain DC, et al. Postoperative analgesic efficacy of intrathecal tramadol versus nalbuphine added to bupivacaine in spinal anaesthesia for lower limb orthopaedic surgery. J Evol Med Dent Sci 2013;2(33):6196-206.

[26] Gurunath BB, Madhusudhana R. Postoperative analgesic efficacy of intrathecal fentanyl compared to nalbuphine with bupivacaine in spinal anaesthesia for lower abdominal surgeries. Anesthesia Essays Researches 2018;12(2):535-8.

[27] Doss NW, Ipe J, Crimi T, et al. Continuous thoracic epidural anesthesia with $0.2 \%$ ropivacaine versus general anesthesia for perioperative management of modified radical mastectomy. Anesth Analg 2001;92(6):1552-7.

[28] Bhattacharyya R, Dutta B. Postoperative analgesia with local anaesthetic and opioid combinations, using double space CSE technique. Indian J Anaesth 2007;51(5):40914. 